\section{The dog did nothing in the night-time}

Sir - The recent Briefing on malaria (Nature 386, 535-540; 1997) highlights the current critical situation. The accompanying Correspondence $(386,541$; 1997), a timely reminder of the need for sustained international collaboration, is signed by individuals representing a broad spectrum of national and international organizations, all supporters and all directly concerned with the problem.

The Scientific and Technological Cooperation with Developing Countries programme (INCO-DC) of the European Commission (EC) Directorate General XII, which was a co-sponsor of the meeting, has for many years supported collaborative North-South research projects in malaria. As European scientists already involved in research networks on malaria supported by INCO-DC, we were surprised at the absence of an EC signatory to the letter. The $\mathrm{EC}$ is mandated to embrace complex issues at the forefront of international collaboration, issues likely to be resolved only through the joint efforts of scientists from the developing countries and from the North.

The European Union harbours underexploited potential, which might be harnessed within the EC, for coordination of the links between development and research funding. This would strengthen both research on malaria and the ability to develop and sustain control programmes within reinforced health services. The increased awareness of the scale of the malaria problem is also timely in the light of current discussions on the content of the Fifth Framework Programme. If Europe really has a serious commitment to solving the problems of malaria, it must seize now the opportunity to play a leading role in the global attack on malaria. It is to be hoped that the spirit of Dakar will be met by a committed and urgent response from the EC.

Alan Thomas, Biomedical Research Centre, Rijswijk, The Netherlands, e-mail: thomas@bprc.nl; Andrew Waters, University of Leiden, The Netherlands; Pierre Druilhe, Institut Pasteur, Paris, France; Michael Lanzer, University of Wårzburg, Germany; Mario Coluzzi, University of Rome 'La Sapienza', Italy

Sir - I should like to reassure your readers that the pharmaceutical industry has not totally given up on new treatments for malaria.

Glaxo Wellcome has recently completed development of a new antimalarial, Malarone, a combination of atovaquone and proguanil, which is active against many resistant strains of Plasmodium. The company has already announced a donation programme for this new drug, which is being piloted in Kenya later this year. Although we believe Malarone will have a significant effect globally on malaria, we recognize that Plasmodium has a propensity to develop resistance. So we are actively researching new agents that work by different mechanisms.

Such research activities range from a cooperative screening programme in which Glaxo Wellcome supplies compounds to the World Health Organisation (WHO) for testing against whole parasites to more targeted approaches. Regarding the latter, a number of cDNA sequences for malarial enzymes are appearing in the databases, and lactate dehydrogenase is an example of one such essential enzyme, for which a high-resolution crystal structure has recently been published by Professor J. John Holbrook's group at the University of Bristol (C. R. Dunn et al. Nature Struct. Biol. 3, 912-915; 1996). Comparative studies with its mammalian counterpart indicate significant differences, making this an attractive target for the rational design of new selective and cidal agents for the treatment of malaria. Thus lactate dehydrogenase forms the focus for an international screening programme involving scientists in Bristol and Glaxo Wellcome sites in Madrid and Stevenage, which we hope will become a model for the future. We have every intention of developing any chemical leads that the screening programme provides and will make use of the excellent cooperation provided by our link with WHO.

\section{Mike S. Marriott}

Microbial Diseases Research,

Glaxo Wellcome SpA,

Via A. Fleming 2,

37100 Verona, Italy

Sir - We applaud your articles about the urgent need for new malaria control programmes and for innovative research to guide them.

Your invocation of the legacy of Ronald Ross seems especially apt in this regard, and it reminded us that a critical part of that legacy is his demonstration that the most powerful insights with respect to control derive from research that integrates theory, laboratory and field work. While the advantages of such integrated research programmes may already appear selfevident to readers in the home country of Ross and his illustrious successor, MacDonald, this may be less true elsewhere.

\section{F. Ellis McKenzie} William H. Bossert

Harvard University,

Cambridge, Massachusetts 02138, USA

\section{Cloning humans}

Sir - If there were no other reasons to argue against cloning humans, Mike Fainzilber gives at least one very good one (Nature 386, 431; 1997).

His use of cloning a child dying in an accident as an example of 'good' cloning suggests a concept of life reduced to running a genetic code. Cloning a dying loved onejust like rerunning an accidentally aborted computer program - deeply questions the dignity and value of human life. Furthermore, the knowledge of being a cloned 'reserve copy' of a dead precursor might result in a deep identity problem for the clone if there is more to personality than just the genes.

Nikolaus Nestle

2N Kreative Entwicklungen,

Holdergasse 10,

D-89291 Holzheim, Germany

Sir - Galibert et al argue for a "total and definitive ban" on human cloning on the grounds that "the essence of humanity lies in the uniqueness of each of its members, resulting from the unique recombination of two equally unique genomes" (Nature 386, $431 ; 1997)$. What are we to do with the $\sim 1 \%$ of the population who are already monozygotic twins (the result of 1 in 250 pregnancies) if they are not essentially human?

\section{Mark R. Baker}

University of Oxford,

Radcliffe Infirmary,

Oxford OX2 6HE, UK

e-mail:mark.baker@green.ox.ac.uk

\section{Not quite the same}

Sir-Robert Desowitz, in his review of Deadly Feasts by Richard Rhodes (Nature $386,565 ; 1997)$, describes the author's anger and contempt for various authorities, and says he "serves as a kind of latter-day Sinclair Lewis, who excoriated the Chicago meatpacking industry". Perhaps Desowitz knows that the author of Main Street, Babbitt and Arrowsmith excoriated the meat industry to his friends, but it was Upton Sinclair who did it in print, in The Jungle (1906).

Poor Upton Sinclair is always mistaken for his partial namesake; a pity, because he was an interesting man who made a career out of excoriation. In 1923, he began to read from the Bill of Rights at a rally in San Pedro, and was quickly arrested for "discussing thoughts and theories contemptuous of the State of California". J. J. Cohen

Department of Immunology, B-184,

University of Colorado Medical School,

Denver, Colorado 80262, USA

e-mail:John.Cohen@uchsc.edu 